Article

\title{
Primary Tumor Sidedness, RAS and BRAF Mutations and MSI Status as Prognostic Factors in Patients with Colorectal Liver Metastases Treated with Surgery and Thermal Ablation: Results from the Amsterdam Colorectal Liver Met Registry (AmCORE)
}

\author{
Madelon Dijkstra ${ }^{1, *}{ }^{\oplus}$, Sanne Nieuwenhuizen ${ }^{1}$, Robbert S. Puijk ${ }^{1}$, Florentine E. F. Timmer ${ }^{1}{ }^{\circledR}$, Bart Geboers ${ }^{1}{ }^{\circledR}$, \\ Evelien A. C. Schouten ${ }^{1}$, Jip Opperman ${ }^{2}$, Hester J. Scheffer ${ }^{1}$, Jan J. J. de Vries ${ }^{1}$, Kathelijn S. Versteeg ${ }^{3}$, \\ Birgit I. Lissenberg-Witte ${ }^{4}$, M. Petrousjka van den Tol ${ }^{5}$ and Martijn R. Meijerink ${ }^{1} \mathbb{C}$ \\ 1 Department of Radiology and Nuclear Medicine, Amsterdam University Medical Centers, \\ VU Medical Center Amsterdam, Cancer Center Amsterdam, 1081 HV Amsterdam, The Netherlands; \\ s.nieuwenhuizen1@amsterdamumc.nl (S.N.); r.puijk@amsterdamumc.nl (R.S.P.); \\ check for \\ updates \\ Citation: Dijkstra, M. \\ Nieuwenhuizen, S.; Puijk, R.S.; \\ Timmer, F.E.F.; Geboers, B.; Schouten, \\ E.A.C.; Opperman, J.; Scheffer, H.J.; \\ de Vries, J.J.J.; Versteeg, K.S.; et al. \\ Primary Tumor Sidedness, RAS and \\ BRAF Mutations and MSI Status as \\ Prognostic Factors in Patients with \\ Colorectal Liver Metastases Treated \\ with Surgery and Thermal Ablation: \\ f.timmer1@amsterdamumc.nl (F.E.F.T.); b.geboers@amsterdamumc.nl (B.G.); \\ e.schouten@amsterdamumc.nl (E.A.C.S.); hj.scheffer@amsterdamumc.nl (H.J.S.); \\ j.devries1@amsterdamumc.nl (J.J.J.d.V.); mr.meijerink@amsterdamumc.nl (M.R.M.) \\ 2 Department of Radiology and Nuclear Medicine, Noordwest Ziekenhuisgroep, Location Alkmaar, \\ 1800 AM Alkmaar, The Netherlands; j.opperman@nwz.nl \\ 3 Department of Medical Oncology, Amsterdam University Medical Centers, VU Medical Center Amsterdam, \\ Cancer Center Amsterdam, 1081 HV Amsterdam, The Netherlands; k.versteeg@amsterdamumc.nl \\ 4 Department of Epidemiology and Data Science, Amsterdam University Medical Centers, \\ VU Medical Center Amsterdam, Vrije Universiteit Amsterdam, 1081 HV Amsterdam, The Netherlands; \\ b.lissenberg@amsterdamumc.nl \\ 5 Department of Surgery, Amsterdam University Medical Centers, VU Medical Center Amsterdam, \\ Cancer Center Amsterdam, 1081 HV Amsterdam, The Netherlands; mp.vandentol@amsterdamumc.nl \\ * Correspondence: m.dijkstra3@amsterdamumc.nl; Tel.: +31-20-444-4571
} Results from the Amsterdam Colorectal Liver Met Registry (AmCORE). Biomedicines 2021, 9, 962. https://doi.org/10.3390/ biomedicines 9080962

Academic Editor: Ramon

Garcia Escudero

Received: 29 June 2021

Accepted: 3 August 2021

Published: 5 August 2021

Publisher's Note: MDPI stays neutral with regard to jurisdictional claims in published maps and institutional affiliations.

Copyright: (C) 2021 by the authors Licensee MDPI, Basel, Switzerland. This article is an open access article distributed under the terms and conditions of the Creative Commons Attribution (CC BY) license (https:// creativecommons.org/licenses/by/ $4.0 /)$
Abstract: The aim of this study was to assess primary tumor sidedness of colorectal cancer (CRC), rat sarcoma viral oncogene homolog (RAS) and v-raf murine sarcoma viral oncogene homolog B (BRAF) mutations and microsatellite instability (MSI) status as prognostic factors predicting complications, survival outcomes, and local tumor progression (LTP) following surgery and thermal ablation in patients with colorectal liver metastases (CRLM). This Amsterdam Colorectal Liver Met Registry (AmCORE) based study included 520 patients, 774 procedures, and 2101 tumors undergoing local treatment (resection and/or thermal ablation) from 2000 to 2021. Outcomes following local treatment were analyzed for primary tumor sidedness of CRC, RAS, and BRAF mutations and MSI status. The Kaplan-Meier method was used to estimate local tumor progression-free survival (LTPFS), local control (LC), distant progression-free survival (DPFS), and overall survival (OS). Uni- and multivariable analyses were performed based on Cox proportional hazards model. The chi-square test was used to analyze complications. Complications $(p=0.485)$, OS $(p=0.252)$, LTPFS $(p=0.939)$, and LC ( $p=0.423)$ was not associated with tumor-sidedness. Compared to right-sided colon cancer (CC) (reference HR 1.000), DPFS was superior for left-sided CC and rectal cancer $(p=0.018)$ with an HR for left-sided CC of 0.742 (95\% CI, 0.596-0.923) and for RC of 0.760 (95\% CI, 0.597-0.966). Regarding RAS mutations, no significant difference was found in OS $(p=0.116)$. DPFS $(p=0.001)$, LTPFS ( $p=0.039)$, and LC ( $p=0.025)$ were significantly lower in the RAS mutation group. Though no difference in LTPFS was found between RAS wildtype and RAS mutated CRLM following resection $(p=0.532)$, LTPFS was worse for RAS mutated tumors compared to RAS wildtype following thermal ablation ( $p=0.037)$. OS was significantly lower in the BRAF mutation group $(p<0.001)$ and in the MSI group $(p<0.001)$ following local treatment, while both did not affect DPFS, LTPFS, and LC. This AmCORE based study suggests the necessity of wider margins to reduce LTP rates in patients with RAS mutated CRLM, especially for thermal ablation. Upfront knowledge regarding molecular biomarkers may contribute to improved oncological outcomes. 
Keywords: colorectal cancer (CRC); colorectal liver metastases (CRLM); primary tumor sidedness; local tumor progression; surgery; thermal ablation; microwave ablation (MWA); radiofrequency ablation (RFA); RAS mutation; BRAF mutation; microsatellite instability (MSI)

\section{Introduction}

Colorectal cancer (CRC) represents approximately $10 \%$ of the annual global cancer incidence and is the second frequent cause of death from cancer worldwide [1]. The presence of distant metastases, mostly involving the liver, substantially affects the prognosis of patients with CRC. Colorectal liver metastases (CRLM) develop in up to $50 \%$ of all patients with CRC during the course of disease [2,3]. Five-year overall survival (OS) in untreated CRLM is $<3 \%$ and when administering palliative chemotherapy about $11 \%$ [4-7]. Local treatment of CRLM with curative intent, comprising partial hepatectomy and thermal ablation (i.e., radiofrequency ablation (RFA), microwave ablation (MWA)), reaches 5-year OS of $50-60 \%$ [8-13].

According to the clinical risk score (CRS) for partial hepatectomy and the modified CRS for thermal ablation, well-known prognostic factors are size of the largest CRLM, number of CRLM and carcinoembryonic antigen (CEA) levels at the time of initial diagnosis of metastatic disease, node positive disease and a short ( $<12$ months) disease-free interval between the primary tumor diagnosis and detection of CRLM [14-17].

There is growing attention for the prognostic role of the primary tumor location. Since the right colon (midgut), left colon and rectum (hindgut) develop from different embryological origins, tumor biology varies between right-sided colon cancer (CC), leftsided CC, and rectal cancer (RC) [18]. Primary tumors originating from right-sided CC are associated with a higher frequency of rat sarcoma viral oncogene homolog (RAS) mutations, v-raf murine sarcoma viral oncogene homolog B (BRAF) mutations, and microsatellite instability (MSI) $[19,20]$. Furthermore, right-sided CC showed a worse prognosis in both non-metastatic [21] and metastatic setting [22].

The impact of primary tumor location is relatively well established in outcomes following partial hepatectomy. Although Makowiec et al. found no significant difference in 5-year OS between patients with right-sided versus left-sided CRC $(p=0.64)$ [23], Dupré et al. demonstrated reduced OS rates for right-sided compared to left-sided CC (34.6 versus 45.3 months, $p=0.035$ ) [24]. This was confirmed by Creasy et al. (hazard ratio (HR), 1.22; 95\% CI, 1.02-1.45; $p=0.028$ ) [25]. In addition, Zhang et al. observed an HR of 0.659 (95\% CI, 0.478-0.910; $p=0.011$ ) in recurrence-free survival comparing left-sided CC to right-sided CC after partial hepatectomy [26].

The influence of the primary tumor location on results following thermal ablation, are established by Gu et al. and Zhou et al. [27,28]. Following outcomes after RFA, patients with right-sided CC compared to left-sided CC had a median OS of 29.4 versus 40.3 months, respectively ( $p=0.042)$ [27]. Moreover, comparison of right-sided CC versus left-sided CC showed a significant difference in progression-free survival $(p=0.012)$ in patients treated with MWA [28]. However, to our knowledge, additional research on the role of the primary tumor location in local tumor progression-free survival (LTPFS), distant progression-free survival (DPFS) and OS after thermal ablation for CRLM is limited.

This Amsterdam Colorectal Liver Met Registry (AmCORE) based study aimed to assess primary tumor sidedness of CRC, RAS and BRAF mutations and MSI status as prognostic factors predicting complications, survival outcomes and local tumor progression (LTP) following surgery and thermal ablation in patients with CRLM.

\section{Materials and Methods}

This single-center prospective cohort study was executed at the Amsterdam University Medical Centers-location VU University Medical Center, The Netherlands, a tertiary referral center for hepatobiliary and gastrointestinal malignancies. The AmCORE prospectively 
maintained CRLM database was used for extraction of data. The affiliated Institutional Review Board approved this study (METc Amsterdam University Medical Centers, location VUmc 2021.0121,). The 'Strengthening the Reporting of Observational studies in Epidemiology' (STROBE) guideline was used to report the analyzed study data [29].

\subsection{Patient Selection}

Data of all patients with CRLM were extracted from the prospective database. Additional recollecting of data was performed by retrospectively searching the hospital's electronic patient database when required. Obtained data involved per-patient, per-procedure and per-tumor data. Patients undergoing surgical resection and thermal ablation were included. Patients undergoing stereotactic body radiation therapy (SBRT), irreversible electroporation (IRE), no, unknown, or planned local treatment, with loss to follow-up or unknown primary tumor location, were excluded.

\subsection{Local Treatment}

CRLMs were detected by cross-sectional imaging containing contrast enhanced computed tomography (ceCT) and 18F-fluoro-2-deoxy-D-glucose ( $\left.{ }^{18} \mathrm{~F}-\mathrm{FDG}\right)$ positron emission tomography (PET) - CT scans, using contrast enhanced magnetic resonance imaging (ceMRI) with diffusion-weighted images prior to local treatment. The multidisciplinary tumor board evaluations attended by (interventional) radiologists, oncological or hepatobiliary surgeons, medical oncologists, radiation oncologists, nuclear medicine physicians, gastroenterologists, and pathologists, determined the selection for local treatment and treatment strategy.

The surgical extent, specific technique, approach, and resection margins (with the intention and preoperative estimation of a possible pathological R0 resection) were at the discretion of the performing oncological or hepatobiliary surgeon. Metasectomy was preferred to preserve future liver volume when possible and anatomical resection when necessary.

Thermal ablation was performed by an experienced interventional radiologist (mastery degree in image-guided tumor ablation, having performed or supervised $>100$ thermal ablation procedures), preferably using real-time fluoroscopy computed tomography (CT)guided ( \pm ultrasound) percutaneous approach. Open approaches were performed when CRLM was potentially resectable, CRLMs $>3$ and when distancing of certain delicate structures, such as intestines if a pneumo- or hydrodissection was unfeasible. Though not exclusively, RFA was mostly performed using the RF3000 generator with expandable LeVeen electrodes (Boston Scientific, Marlborough, MA, USA), the RITA system with compatible expandable electrodes (AngioDynamics BV, Amsterdam, The Netherlands) and MWA using the Evident or Emprint (Medtronic-Covidien, Minneapolis, MN, USA) or Solero (AngioDynamics BV, Amsterdam, The Netherlands) generators with compatible antennas. The ablations were performed conformal to the instructions for use provided by the manufacturer and in accordance with the CIRSE quality improvement guidelines (with an intentional tumor free ablation margin $>1 \mathrm{~cm}$ ) [30]. Residual unablated tumor tissue in case of presumed insufficiently ablated margins were retreated with overlapping ablations.

As (neo-)adjuvant chemotherapy is not standard of care conformal to national guidelines, no patients received neo-adjuvant or adjuvant systemic therapy [31]. However, patients did receive induction chemotherapy when initially unsuitable for resection/thermal ablation (downstaging chemotherapy), when chemotherapy was likely to reduce procedural risk (risk-reducing chemotherapy) or when liver metastatic disease developed early after primary tumor diagnosis (test-of-tumor biology). MSI, RAS-, and BRAF-mutation status were not routinely established nor taken into account when discussing local treatment options for patients in the multidisciplinary tumor board.

\subsection{Follow-up}

In the first year 3/4-monthly, in the 2nd and 3rd year 6-monthly, and in the 4th and 5 th year 12 monthly after local treatment ${ }^{18}$ F-FDG-PET-CT with diagnostic ceCTs of the 
chest and abdomen were performed, according to national guidelines [31]. A ceMRI with diffusion-weighted images was used as problem solver. A ceCT-scan was performed within one to six weeks after the repeat local treatment, in the context of a presumably incomplete local treatment procedure. LTP was defined as an unequivocally and solid enlarging mass or focal ${ }^{18}$ F-FDG PET avidity at the surface of the ablated tumor for thermally ablated tumors or histopathological confirmation in case of uncertainty.

\subsection{Data Collection and Statistical Analysis}

Patient, procedure, and tumor characteristics were obtained from the AmCORE database. Categorical variables are reported as percentages and continuous variables are reported as mean with standard deviation (SD) when normally distributed and as median with interquartile range (IQR) when not-normally distributed.

The assessed endpoints were local tumor progression-free survival (LTPFS), local control (LC), distant progression-free survival (DPFS), and overall survival (OS), defined as time-to-event from local treatment. Death without local or distant progression (competing risk) was censored. Complications were reported using Common Terminology Criteria for Adverse Events (CTCAE) [32]. Outcomes following local treatment were analyzed for primary tumor sidedness of colorectal cancer (CRC), RAS, and BRAF mutations and MSI status. Kaplan-Meier curves and Gehan-Breslow-Wilcoxon test was used to estimate and compare the primary endpoints LTPFS, to account for the events at early time points as LTP develops mostly early after local treatment. Kaplan-Meier method curves and the log-rank test was used to estimate and compare OS, DPFS, and LC. The Pearson chi-square test was used to compare complications. Uni- and multivariable analyses of primary endpoint LTPFS was performed based on Cox proportional hazards regression comparing right-sided CC, to left-sided CC, and to RC. Variables with $p \leq 0.050$ in univariable analysis were included in multivariable analysis using backward selection procedure. Variables were considered significant when $p=0.050$, other variables were removed step by step. Hazard ratio (HR) and 95\% confidence interval (95\% CI) were evaluated.

Statistical analyses were supported by an biostatistician (BLW) and performed using SPSS ${ }^{\circledR}$ Version 24.0 (IBM ${ }^{\circledR}$ Corp, Armonk, NY, USA) [33] and R version 4.0.3. (R Foundation, Vienna, Austria) [34].

\section{Results}

A total of 915 patients, 1415 procedures, and 3316 tumors were identified from the AmCORE database (Figure 1). Further selection revealed 520 patients, 774 procedures, and 2101 tumors undergoing local treatment between 2000 and 2021 for inclusion in the analyses. Patients treated with IRE $(n=69)$, SBRT $(n=83)$, no, unknown, or planned local treatment $(n=155)$, with loss to follow-up $(n=84)$ and with unknown primary tumor location $(n=4)$ were excluded.

\subsection{Patient-, Disease-, Procedure-, and Tumor-Related Characteristics}

Table 1 presents baseline patient, procedure and tumor characteristics of the included 520 patients, 774 procedures, and 2101 tumors. The age of the treated patients ranged between 22 and 90 years old. Overall, median number of tumors per procedure was 2.0 (IQR 1.0-4.0) and median size per tumor was $16 \mathrm{~mm}$ (IQR 9.0-25.0). Median follow-up time after local treatment was 19.5 months and median length of hospital stay of the entire cohort was 4.0 days (IQR 1.0-6.0). 


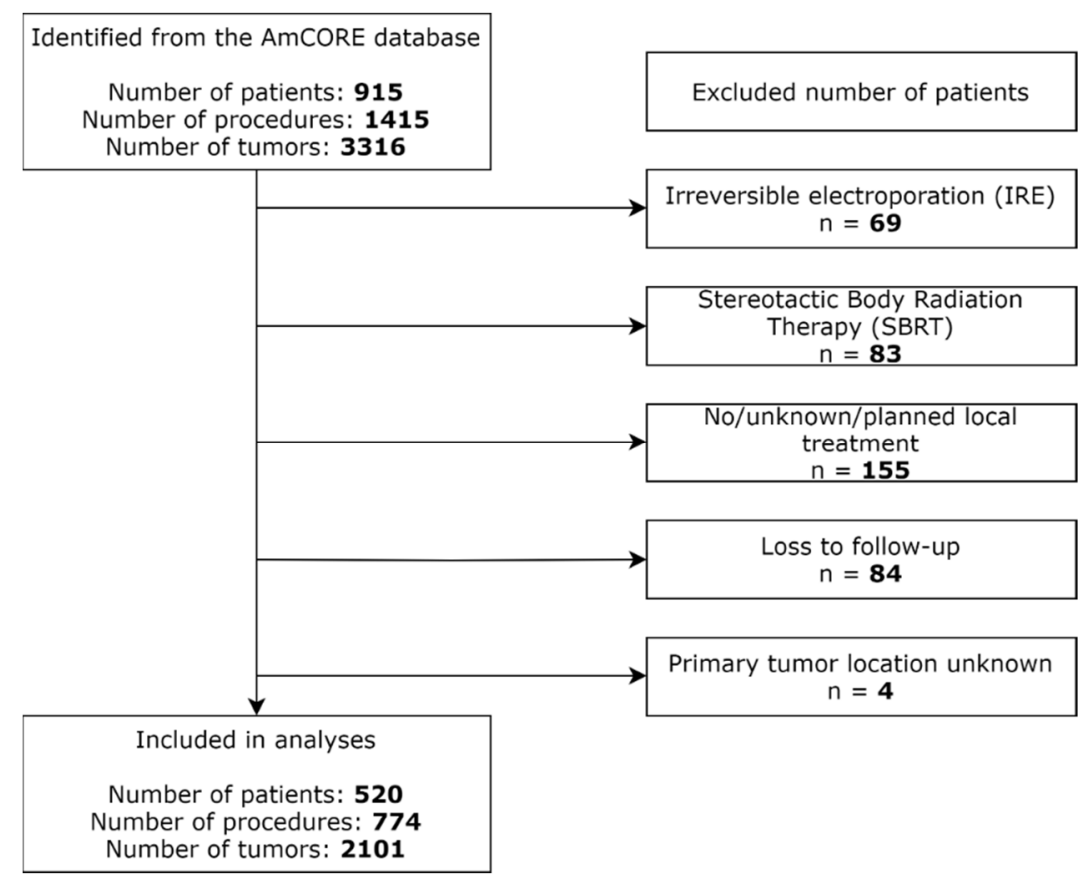

Figure 1. Flowchart of included and excluded patients.

Table 1. Patient-, procedure-, and tumor-related characteristics.

\begin{tabular}{|c|c|c|}
\hline \multicolumn{2}{|c|}{ Patient-Related Characteristics } & $n=520$ \\
\hline \multirow{2}{*}{ Gender } & Male & 66.5 \\
\hline & Female & 33.5 \\
\hline Age (years) * & & $65.5(12.0)$ \\
\hline \multirow{4}{*}{ ASA physical status } & 1 & 7.0 \\
\hline & 2 & 69.9 \\
\hline & 3 & 22.7 \\
\hline & 4 & 0.4 \\
\hline \multirow{3}{*}{ Comorbidities } & None & 49.2 \\
\hline & Minimal & 37.0 \\
\hline & Major & 13.8 \\
\hline BMI $\left(\mathrm{kg} / \mathrm{cm}^{2}\right)^{*}$ & & $25.8(4.4)$ \\
\hline \multicolumn{2}{|c|}{ Disease-Related Characteristics } & $n=520$ \\
\hline \multirow{2}{*}{ First diagnosis of CRLM } & Synchronous & 50.6 \\
\hline & Metachronous & 49.4 \\
\hline \multirow{3}{*}{$\begin{array}{l}\text { Size of largest metastasis at first diagnosis of } \\
\text { CRLM (mm) }\end{array}$} & Small (1-30) & 63.6 \\
\hline & Intermediate (31-50) & 24.5 \\
\hline & Large $(>50)$ & 11.9 \\
\hline \multirow{3}{*}{ Number of tumors at first diagnosis of CRLM } & 1 & 36.3 \\
\hline & $2-5$ & 48.1 \\
\hline & $>5$ & 15.6 \\
\hline \multirow{2}{*}{ Extrahepatic disease at first diagnosis of CRLM } & No & 89.4 \\
\hline & Yes & 10.6 \\
\hline \multirow{3}{*}{ Primary tumor location } & Right-sided CC & 25.0 \\
\hline & Left-sided CC & 40.4 \\
\hline & $\mathrm{RC}$ & 34.6 \\
\hline \multirow[t]{3}{*}{ RAS status (any) } & RAS wildtype & 8.3 \\
\hline & RAS mutation & 6.9 \\
\hline & Unknown & 84.8 \\
\hline
\end{tabular}


Table 1. Cont.

\begin{tabular}{|c|c|c|}
\hline \multicolumn{2}{|c|}{ Patient-Related Characteristics } & \multirow{2}{*}{$\begin{array}{c}n=\mathbf{5 2 0} \\
12.1\end{array}$} \\
\hline BRAF V600 status & BRAF wildtype & \\
\hline & BRAF mutation & 1.2 \\
\hline & Unknown & 86.7 \\
\hline \multirow[t]{3}{*}{ MSS/MSI status } & MSS & 23.8 \\
\hline & MSI & 0.8 \\
\hline & Unknown & 75.4 \\
\hline \multicolumn{2}{|c|}{ Procedure-Related Characteristics } & $n=774$ \\
\hline \multirow{3}{*}{ Local treatment } & Resection & 27.3 \\
\hline & Thermal ablation & 48.3 \\
\hline & Combination & 24.4 \\
\hline \multirow{2}{*}{ Chemotherapy } & No & 76.1 \\
\hline & Yes & 23.9 \\
\hline \multirow{2}{*}{ Procedure number in course of treatment } & 1 st & 67.4 \\
\hline & 2nd-5th & 32.6 \\
\hline \multirow{3}{*}{ Number of tumors } & 1 & 38.3 \\
\hline & $2-5$ & 48.7 \\
\hline & $>5$ & 13.1 \\
\hline \multirow{3}{*}{ Approach } & Open & 58.4 \\
\hline & Laparoscopic & 7.8 \\
\hline & Percutaneous & 33.8 \\
\hline \multirow{3}{*}{ Anesthesia } & Midazolam sedation & 6.1 \\
\hline & Propofol sedation & 16.8 \\
\hline & General anesthesia & 82.8 \\
\hline \multicolumn{2}{|c|}{ Tumor-Related Characteristics } & $n=2101$ \\
\hline \multirow{3}{*}{ Size (mm) } & Small (1-30) & 84.5 \\
\hline & Intermediate (31-50) & 12.4 \\
\hline & Large $(>50)$ & 3.1 \\
\hline \multirow{2}{*}{ Margin size (mm) } & $0-5$ & 13.8 \\
\hline & $>5$ & 86.2 \\
\hline Local treatment & $\begin{array}{c}\text { Resection } \\
\text { Thermal ablation }\end{array}$ & $\begin{array}{l}36.6 \\
63.4\end{array}$ \\
\hline
\end{tabular}

Values are reported as percentage of patients, ${ }^{*}=$ continuous variables reported as mean (standard deviation $\mathrm{SD})$, right-sided CC = right-sided colon cancer, left-sided CC = left-sided colon cancer, $\mathrm{RC}=$ rectal cancer, ASA = American Society of Anesthesiologists score, BMI = body mass index.

\subsection{Primary Tumor Sidedness}

No differences in complication rates $(p=0.352)$ and grades $(p=0.485)$ were found following local treatment of CRLM originating from right-sided CC, left-sided CC, and RC with complications in $24.2 \%$ in the right-sided CC group, $26.7 \%$ in the left-sided CC group, and $30.5 \%$ in the RC group (overall complication rate of $27.2 \%$ ) (Table 2).

Table 2. Complications of local treatment per primary tumor location and RAS status (CTCAE) [32].

\begin{tabular}{|c|c|c|c|c|c|c|c|c|}
\hline Grade & $\begin{array}{c}\text { Total } \\
n=774\end{array}$ & $\begin{array}{c}\text { Right-Sided CC } \\
\quad n=204\end{array}$ & $\begin{array}{c}\text { Left-Sided CC } \\
\quad n=336\end{array}$ & $\begin{array}{c}\mathrm{RC} \\
n=234\end{array}$ & $p$-Value & $\begin{array}{c}\text { RAS-wt } \\
n=43\end{array}$ & $\begin{array}{c}\text { RAS-mut } \\
n=36\end{array}$ & $p$-Value \\
\hline Total & 27.2 & 24.2 & 26.7 & 30.5 & $0.352^{a}$ & 24.6 & 25.0 & $0.961^{a}$ \\
\hline Grade 1 & 5.0 & 5.7 & 4.4 & 5.1 & & 4.6 & 5.4 & \\
\hline Grade 2 & 8.6 & 7.3 & 8.5 & 9.8 & & 9.2 & 10.7 & \\
\hline Grade 3 & 10.1 & 7.3 & 9.7 & 13.1 & & 7.7 & 7.1 & \\
\hline Grade 4 & 2.1 & 3.6 & 1.9 & 0.9 & & 1.5 & 1.8 & \\
\hline Grade 5 & 1.0 & 0.5 & 1.3 & 0.9 & $0.485^{\mathrm{a}}$ & 1.5 & 0.0 & $0.964^{\mathrm{a}}$ \\
\hline
\end{tabular}

Values are reported as percentage of patients, right-sided CC $=$ right-sided colon cancer, left-sided CC $=$ left-sided colon cancer, $\mathrm{RC}=$ rectal cancer, RAS-wt $=$ RAS wildtype, RAS-mut $=$ RAS mutation, ${ }^{\text {a }}=$ Pearson chi-square. 
Median OS of the entire cohort was 52.0 months. Median OS following local treatment in the right-sided CC group was 38.8 months, in the left-sided CC group 52.9 months, and in the RC group 45.5 months (Figure 2a). In the right-sided CC group, 1-year OS was $90.7 \%$, 3-year OS was $50.2 \%$, and 5-year OS was $47.5 \%$. In the left-sided CC group, $1-, 3-$, and 5 -year OS were, respectively, $92.9 \%, 69.9 \%$, and $48.2 \%$. Then, for $1-, 3-$, and 5 -year OS, respectively, $92.1 \%, 69.5 \%$, and $37.1 \%$ were found in the RC group. Compared to right-sided CC (reference HR 1.000), OS was not significantly different for left-sided CC and RC ( $p=0.254)$ with an HR for left-sided CC of 0.725 (95\% CI, 0.481-1.093) and for RC of 0.917 (95\% CI, 0.601-1.398).
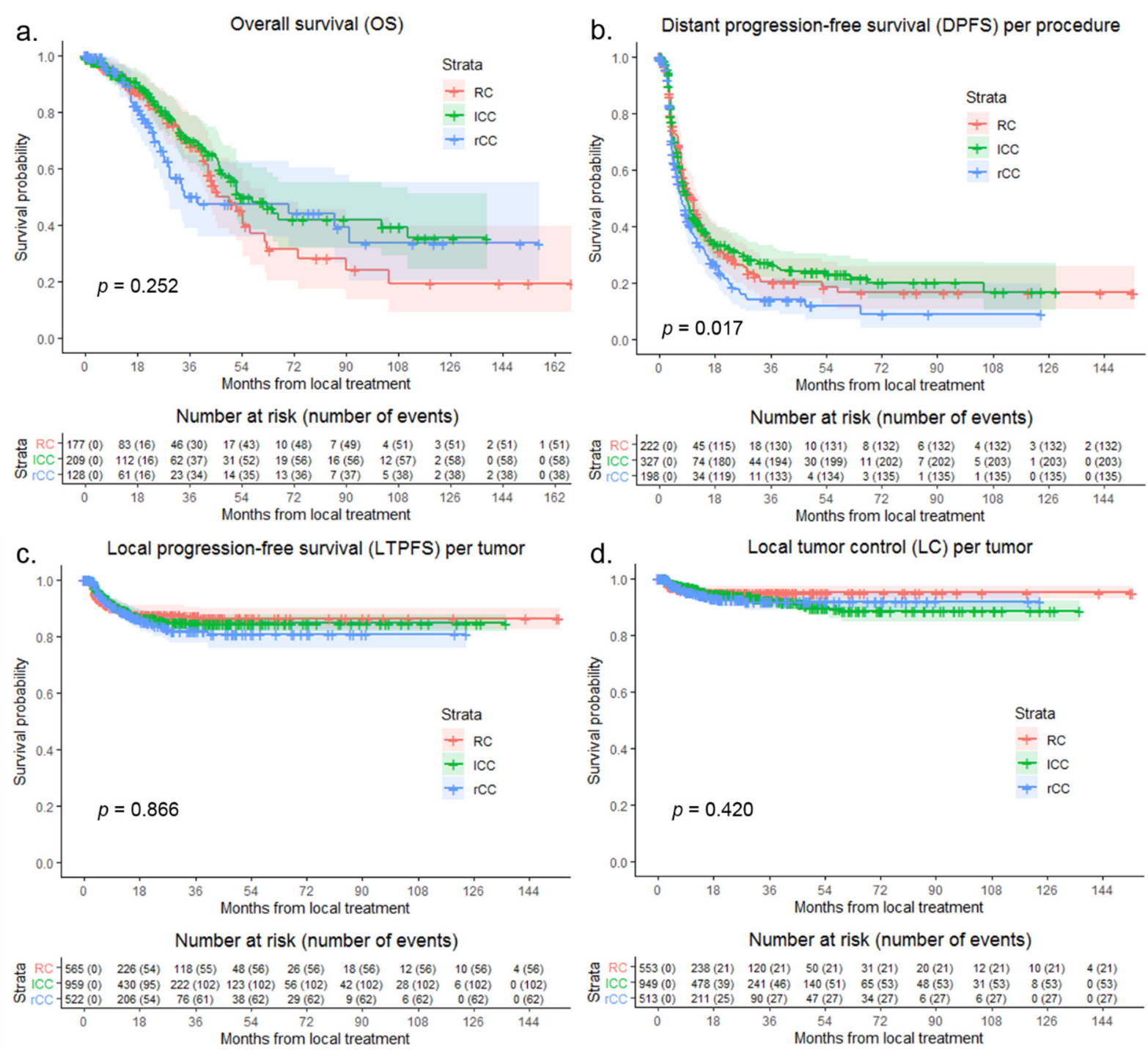

Figure 2. Kaplan-Meier curves, with log-rank (Mantel-Cox) test or Gehan-Breslow-Wilcoxon test, of (a) overall survival (OS) per patient $(p=0.252)$, (b) distant progression-free survival (DPFS) per procedure $(p=0.017)$, (c) local tumor progressionfree survival (LTPFS) per tumor ( $p=0.866)$, and (d) of local control (LC) per tumor $(p=0.420)$ after local treatment comparing RC (pink), left-sided CC (green) and right-sided CC (blue). Numbers at risk (number of events) are per patient, per procedure and per tumor. Death without distant progression, local tumor progression (LTP) or loss of LC (competing risk) is censored.

Median DPFS following local treatment in the right-sided CC group was 6.9 months, in the left-sided CC group 9.0 and in the RC group 10.5 months (Figure 2b). In the right-sided CC group, 1-year DPFS was 35.3\%, 3-year DPFS was $14.1 \%$ and 5 -year DPFS was $12.1 \%$. In the left-sided CC group, 1-, 3-, and 5-year DPFS were, respectively, 42.2\%, 27.2\%, and 
23.2\%. Then, for 1-, 3-, and 5-year DPFS, respectively, 44.8\%, 20.3\%, and 16.7\% were found in the RC group. Compared to right-sided CC (reference HR 1.000), DPFS was superior for left-sided CC and RC ( $p=0.018)$ with an HR for left-sided CC of 0.742 (95\% CI, 0.596-0.923) and for RC of 0.760 (95\% CI, 0.597-0.966).

LTP was reported at follow-up after local treatment of CRLM in 10.8\% of tumors, $11.9 \%$ in right-sided CC group, $10.6 \%$ in the left-sided CC group, and $9.9 \%$ in the RC group (Figure 2c). Then, for 1-, 3-, and 5-year LTPFS, respectively, 89.0\%, 81.9\% and 80.7\% were found in the right-sided CC group; $89.4 \%, 84.7 \%$, and $84.7 \%$ in the left-sided CC group; and $89.2 \%, 87.1 \%$, and $86.2 \%$ in the RC group.

No significant difference in crude, univariable comparison of LTPFS following local treatment was found ( $p=0.559)$ between right-sided CC and left-sided CC (HR, 0.873; 95\% CI, 0.636-1.197) and between right-sided CC and RC (HR, 0.843; 95\% CI, 0.587-1.210). Factors potentially associated with LTPFS found in univariable analysis, as well as not significant associated variables in multivariable analysis are demonstrated in Table 3. Corrected multivariable analysis consisted of number of tumors at first diagnosis $(p=0.002)$, approach $(p<0.001)$, anesthesia technique $(p<0.001)$, appearance of CRLM (new vs. local recurrence, $p<0.001)$, size of metastasis $(p=0.006)$, and margin size $(p<0.001)$. Adjusted HR of left-sided CC compared to right-sided CC was 1.000 (95\% CI, 0.654-1.530) and RC compared to right-sided CC was 0.931 (95\% CI, 0.594-1.460) $(p=0.939)$.

Table 3. Univariable and multivariable Cox regression analysis to detect variables associated with local tumor progressionfree survival (LTPFS).

\begin{tabular}{|c|c|c|c|c|c|}
\hline & & \multicolumn{2}{|c|}{ Univariable Analysis } & \multicolumn{2}{|c|}{ Multivariable Analysis } \\
\hline & & HR (CI) & $p$-Value & HR (CI) & $p$-Value \\
\hline \multirow{3}{*}{ CRC } & Right-sided CC & Reference & \multirow[t]{3}{*}{0.599} & Reference & \multirow[t]{3}{*}{0.939} \\
\hline & Left-sided CC & $0.873(0.636-1.197)$ & & $1.000(0.654-1.530)$ & \\
\hline & $\mathrm{RC}$ & $0.843(0.587-1.210)$ & & $0.931(0.594-1.460)$ & \\
\hline \multicolumn{6}{|c|}{ Patient-related factors } \\
\hline \multirow{2}{*}{ Gender } & Male & Reference & \multirow[t]{2}{*}{0.494} & & \\
\hline & Female & $0.904(0.676-1.208)$ & & & \\
\hline \multicolumn{2}{|c|}{ Age (years) } & 1.007 (0.995-1.018) & 0.249 & & \\
\hline \multirow{4}{*}{ ASA physical status } & 1 & Reference & \multirow[t]{4}{*}{0.224} & & \\
\hline & 2 & $1.060(0.635-1.771)$ & & & \\
\hline & 3 & $0.722(0.401-1.302)$ & & & \\
\hline & 4 & $*$ & & & \\
\hline \multirow{3}{*}{ Comorbidities } & None & Reference & \multirow[t]{3}{*}{0.824} & & \\
\hline & Minimal & $0.978(0.736-1.300)$ & & & \\
\hline & Major & $0.871(0.565-1.344)$ & & & \\
\hline \multicolumn{2}{|c|}{$\mathrm{BMI}\left(\mathrm{kg} / \mathrm{cm}^{2}\right)$} & $1.000(0.971-1.029)$ & \multicolumn{2}{|l|}{0.984} & \\
\hline \multirow{2}{*}{ First diagnosis of CRLM } & Metachronous & Reference & \multirow[t]{2}{*}{$<0.001$} & Reference & \multirow[t]{2}{*}{0.373} \\
\hline & Synchronous & $0.560(0.427-0.734)$ & & $1.191(0.810-1.751)$ & \\
\hline \multirow{3}{*}{$\begin{array}{l}\text { Size of largest metastasis at } \\
\text { first diagnosis of CRLM (mm) }\end{array}$} & Small (1-30) & Reference & \multirow[t]{3}{*}{0.001} & Reference & \multirow[t]{3}{*}{0.712} \\
\hline & Intermediate (31-50) & $1.613(1.176-2.213)$ & & $1.108(0.704-1.742)$ & \\
\hline & Large $(>50)$ & 1.903 (1.251-2.895) & & $1.336(0.655-2.724)$ & \\
\hline \multirow{3}{*}{$\begin{array}{c}\text { Number of tumors at first } \\
\text { diagnosis of CRLM }\end{array}$} & 1 & Reference & \multirow[t]{3}{*}{$<0.001$} & Reference & \multirow[t]{3}{*}{0.002} \\
\hline & $2-5$ & $0.617(0.448-0.849)$ & & $0.931(0.618-1.402)$ & \\
\hline & $>5$ & $0.262(0.176-0.391)$ & & $0.416(0.242-0.714)$ & \\
\hline \multirow{2}{*}{ Extrahepatic disease } & No & Reference & \multirow[t]{2}{*}{0.807} & & \\
\hline & Yes & $0.941(0.580-1.529)$ & & & \\
\hline \multicolumn{6}{|c|}{ Procedure-related factors } \\
\hline \multirow{3}{*}{ Local treatment } & Resection & Reference & \multirow[t]{3}{*}{$<0.001$} & Reference & \multirow[t]{3}{*}{0.055} \\
\hline & Thermal ablation & 1.455 (1.000-2.118) & & $2.234(1.157-4.312)$ & \\
\hline & Combination & $0.714(0.471-1.081)$ & & $1.553(0.806-2.991)$ & \\
\hline Chemotherany & No & Reference & $<0.001$ & Reference & 0.199 \\
\hline Chemotherapy & Yes & $0.485(0.357-0.659)$ & & $0.753(0.488-1.161)$ & \\
\hline
\end{tabular}


Table 3. Cont.

\begin{tabular}{|c|c|c|c|c|c|}
\hline & & \multicolumn{2}{|c|}{ Univariable Analysis } & \multicolumn{2}{|c|}{ Multivariable Analysis } \\
\hline & & $\mathrm{HR}(\mathrm{CI})$ & $p$-Value & $\mathrm{HR}(\mathrm{CI})$ & $p$-Value \\
\hline $\begin{array}{l}\text { Procedure number in course } \\
\text { of treatment }\end{array}$ & $\begin{array}{c}\text { 1st } \\
\text { 2nd-5th }\end{array}$ & $\begin{array}{c}\text { Reference } \\
2.341(1.785-3.069)\end{array}$ & $<0.001$ & $\begin{array}{c}\text { Reference } \\
0.624(0.356-1.093)\end{array}$ & 0.099 \\
\hline Number of tumors & $\begin{array}{c}1 \\
2-5 \\
>5\end{array}$ & $\begin{array}{c}\text { Reference } \\
0.464(0.339-0.633) \\
0.160(0.105-0.242)\end{array}$ & $<0.001$ & $\begin{array}{c}\text { Reference } \\
0.818(0.492-1.360) \\
0.542(0.226-1.295)\end{array}$ & 0.385 \\
\hline Approach & $\begin{array}{c}\text { Open } \\
\text { Laparoscopic } \\
\text { Percutaneous }\end{array}$ & $\begin{array}{c}\text { Reference } \\
0.771(0.315-1.885) \\
2.999(2.285-3.938)\end{array}$ & $<0.001$ & $\begin{array}{c}\text { Reference } \\
0.217(0.030-1.567) \\
3.138(1.885-5.226)\end{array}$ & $<0.001$ \\
\hline Anesthesia & $\begin{array}{l}\text { Midazolam sedation } \\
\text { Propofol sedation } \\
\text { General anesthesia }\end{array}$ & $\begin{array}{c}\text { Reference } \\
0.192(0.110-0.336) \\
0.183(0.124-0.270)\end{array}$ & $<0.001$ & $\begin{array}{c}\text { Reference } \\
0.260(0.142-0.476) \\
0.645(0.344-1.208)\end{array}$ & $<0.001$ \\
\hline \multicolumn{6}{|c|}{ Tumor-related factors } \\
\hline Appearance & $\begin{array}{l}\text { New tumor } \\
\text { Local recurrence }\end{array}$ & $\begin{array}{c}\text { Reference } \\
5.527(4.119-7.417)\end{array}$ & $<0.001$ & $\begin{array}{c}\text { Reference } \\
2.675(1.742-4.107)\end{array}$ & $<0.001$ \\
\hline Size of metastasis (mm) & $\begin{array}{c}\text { Small }(1-30) \\
\text { Intermediate }(31-50) \\
\text { Large }(>50)\end{array}$ & $\begin{array}{c}\text { Reference } \\
2.229(1.597-3.110) \\
4.131(2.465-6.923)\end{array}$ & $<0.001$ & $\begin{array}{c}\text { Reference } \\
1.575(1.020-2.430) \\
2.927(1.392-6.157)\end{array}$ & 0.006 \\
\hline Margin size & $\begin{array}{l}<5 \mathrm{~mm} \\
>5 \mathrm{~mm}\end{array}$ & $\begin{array}{c}\text { Reference } \\
0.382(0.266-0.550)\end{array}$ & $<0.001$ & $\begin{array}{c}\text { Reference } \\
0.424(0.279-0.645)\end{array}$ & $<0.001$ \\
\hline
\end{tabular}

$\mathrm{HR}=$ hazard ratio, $\mathrm{CI}=95 \%$ confidence interval, right-sided $\mathrm{CC}=$ right-sided colon cancer, left-sided $\mathrm{CC}=$ left-sided colon cancer, $\mathrm{RC}=$ rectal cancer, ASA = American Society of Anesthesiologists score, ${ }^{*}$ insufficient group comparison, BMI $=$ body mass index. Using backward selection procedure, results of step by step removed variables were reported. Results are from last step of removal.

Eventual loss of LC at follow-up was reported in $5.0 \%$ of tumors, $5.3 \%$ in the rightsided CC group, 5.6\% in the left-sided CC group, and 3.8\% in the RC group after local treatment (Figure 2d). Then, for 1-, 3-, and 5-year LC, respectively, 95.0\%, 91.8\%, and 91.8\% were found in the right-sided CC group; $96.5 \%, 92.4 \%$, and $88.4 \%$ in the left-sided CC group; and 95.7\%, 95.1\%, and 95.1\% in the RC group. Compared to right-sided CC (reference HR 1.000), LC was not significantly different for left-sided CC and RC ( $p=0.423)$ with an HR for left-sided CC of 0.956 (95\% CI, 0.601-1.521) and for RC of 0.706 (95\% CI, 0.399-1.249).

\subsection{RAS and BRAF Mutations and MSI Status}

With a complication rate of $24.6 \%$ in the RAS mutation group and $25.0 \%$ in the RASwildtype group $(p=0.961)$, the frequencies $(p=0.961)$ did not differ, nor did the grades $(p=0.964)$. No significant differences in complication rates were found for BRAF $(p=0.586)$ and MSI ( $p=0.346)$ either (Table 2$)$.

A total of 43 patients with RAS wildtype and 36 patients with RAS mutation were identified from the AmCORE database. Comparing RAS wildtype to RAS mutation, $86.9 \%$ of tumors had RAS mutation in the right-sided CC group, 27.9\% in the left-sided CC group, and $40.7 \%$ in the RC group $(p<0.001)$. Figure 3 shows survival curves of OS, DPFS, LTPFS, and LC comparing RAS wildtype to RAS mutation. No significant difference was found in OS $(p=0.116)$. DPFS $(p=0.001)$, LTPFS $(p=0.039)$, and LC $(p=0.025)$ were significantly worse in the RAS mutation group.

Subgroup analyses of LTPFS for resection and thermal ablation comparing RAS wildtype to RAS mutation are shown in Figure 4. No difference was found in LTPFS comparing RAS wildtype to RAS mutation following resection $(p=0.532)$. LTPFS was significantly lower in the RAS mutation group compared to the RAS wildtype group following thermal ablation $(p=0.037)$. 


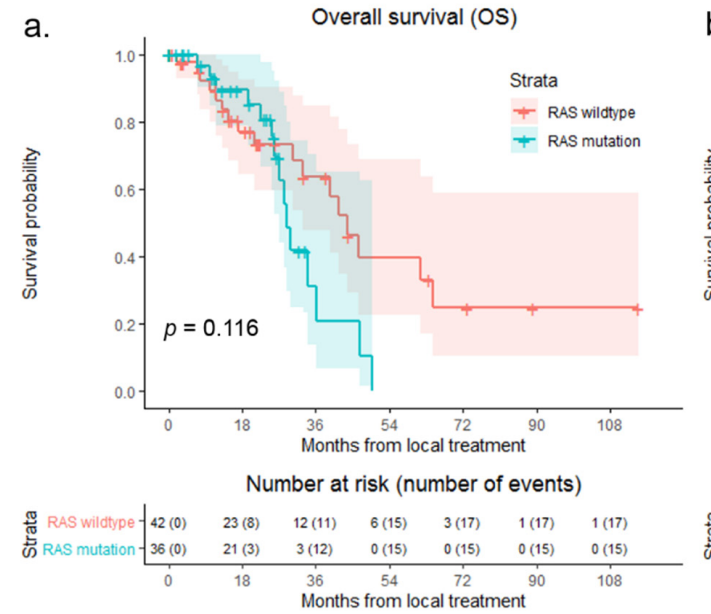

C.

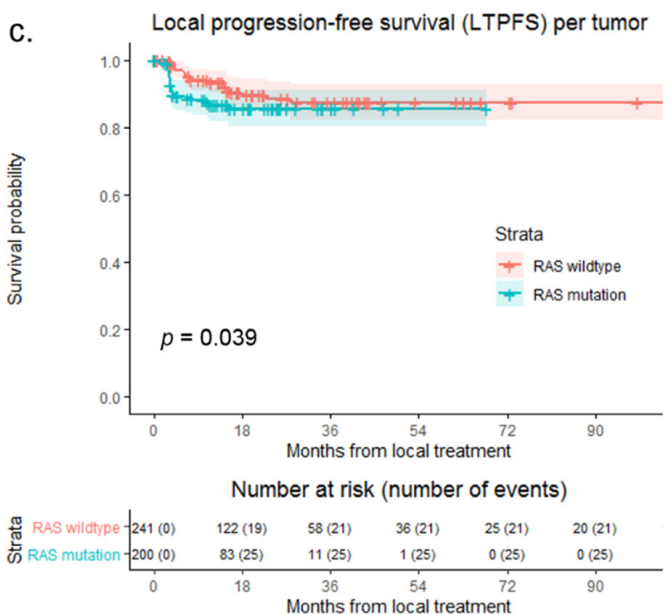

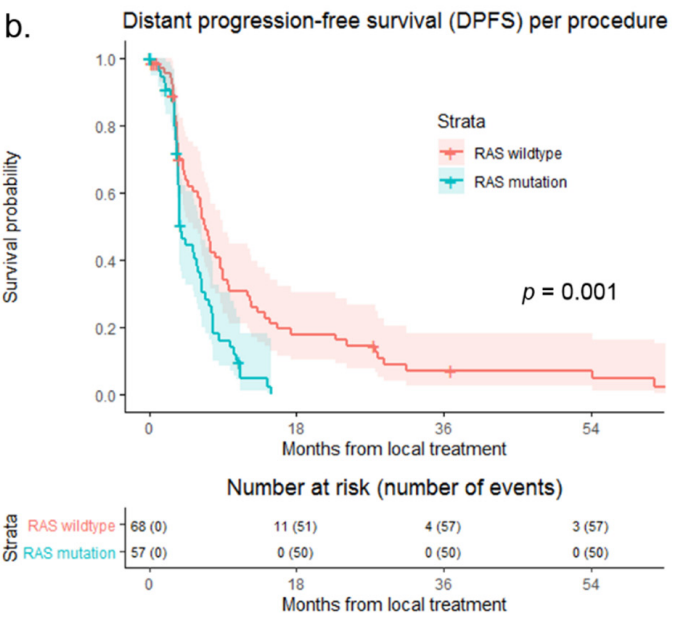

d.

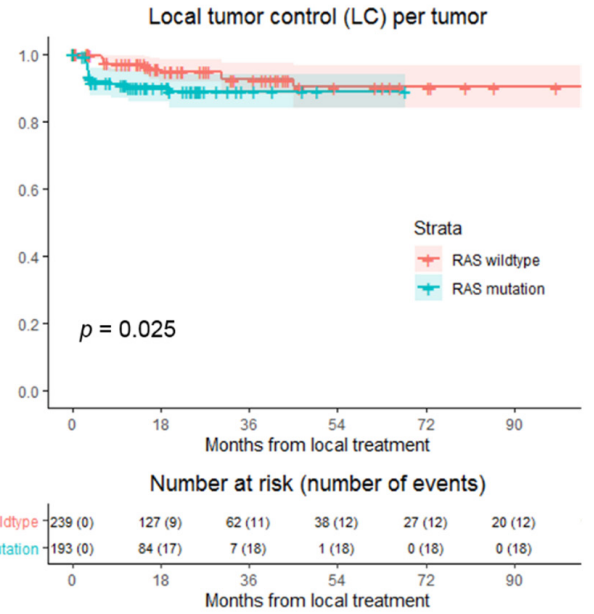

Figure 3. Kaplan-Meier curves, with log-rank (Mantel-Cox) test or Gehan-Breslow-Wilcoxon test, of (a) overall survival (OS) per patient $(p=0.116)$, (b) distant progression-free survival (DPFS) per procedure $(p=0.001)$, (c) local tumor progressionfree survival (LTPFS) per tumor $(p=0.039)$, and (d) of local control (LC) per tumor $(p=0.025)$ after local treatment comparing RAS wildtype (blue) to RAS mutation (pink). Numbers at risk (number of events) are per patient, per procedure and per tumor. Death without distant progression, local tumor progression (LTP), or loss of LC (competing risk) is censored.

a.

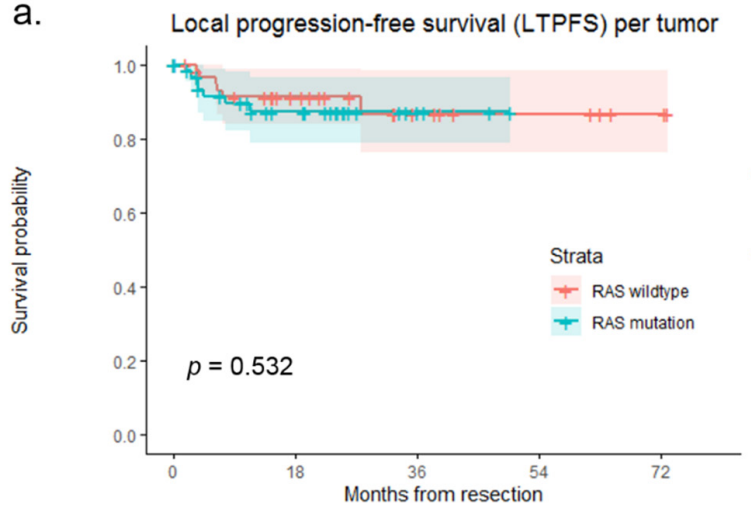

Number at risk (number of events)

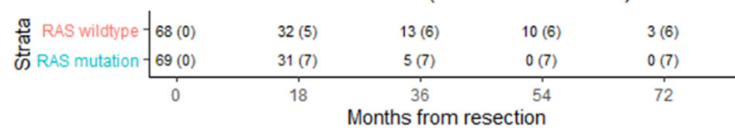

b.

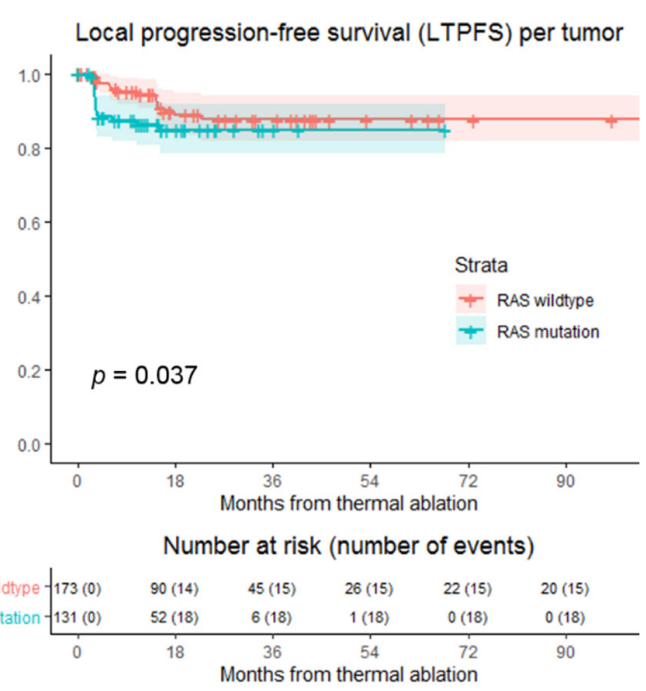

Figure 4. Kaplan-Meier curves with Gehan-Breslow-Wilcoxon test, of (a) local tumor progression-free survival (LTPFS) per tumor following resection $(p=0.532)$ and $(\mathbf{b})$ LTPFS per tumor following thermal ablation $(p=0.037)$ comparing RAS wildtype (blue) to RAS mutation (pink). Numbers at risk (number of events) are per tumor. Death without local tumor progression (LTP; competing risk) is censored. 
Identification of patients from the AmCORE database with BRAF wildtype/mutation revealed 63 patients with BRAF wildtype and 6 patients with BRAF mutation. Comparing BRAF wildtype to BRAF mutation, $11.6 \%$ of tumors had BRAF mutation in the rightsided CC group, $4.7 \%$ in the left-sided CC group, and $0.0 \%$ in the $\operatorname{RC}$ group $(p=0.001)$. OS $(p<0.001)$ was significantly worse in the BRAF mutation group. DPFS $(p=0.075)$, LTPFS $(p=0.679)$, and LC $(p=0.968)$ were not significantly different comparing BRAF wildtype to BRAF mutation.

A total of 124 patients with MSS and 4 patients with MSI were revealed from the AmCORE database. Comparing MSS to MSI, 3.5\% of tumors had MSI in the right-sided CC group, $3.0 \%$ in the left-sided CC group, and $0.0 \%$ in the RC group $(p=0.073)$. OS $(p<0.001)$ was significantly lower in the MS instability group. DPFS $(p=0.316)$, LTPFS $(p=0.342)$, and LC ( $p=0.968)$ were not significantly different comparing MSS to MSI.

\section{Discussion}

Compared to right-sided CC, DPFS was superior for left-sided CC and RC ( $p=0.018)$ with an HR for left-sided CC of 0.742 (95\% CI, 0.596-0.923) and for RC of 0.760 (95\% CI, $0.597-0.966)$. DPFS ( $p=0.001)$, LTPFS $(p=0.039)$, and LC $(p=0.025)$ were significantly lower for patients with RAS mutated tumors. Though, in subgroup analysis, no difference in LTPFS was found between RAS wildtype and RAS mutated CRLM following resection $(p=0.532)$, LTPFS was worse for RAS mutated tumors compared to RAS wildtype tumors following thermal ablation $(p=0.037)$. OS was significantly lower in the BRAF mutation group $(p<0.001)$, while BRAF mutation did not significantly affect DPFS ( $p=0.075)$, LTPFS $(p=0.679)$ and LC $(p=0.968)$. In the MSI group, OS $(p<0.001)$ was significantly lower.

These results imply that information regarding the sidedness of the primary tumor, RAS and BRAF mutations and MSI status are prognostic biomarkers that preferably should be taken into consideration when discussing curative intent therapeutic options for locally treatable CRLM patients. Given the higher LTP rate, physicians should endeavor wider safety-margins for resections and thermal ablation for RAS mutated CRLM.

Compared to left-sided CRC, Dupré et al. showed decreased OS rates (34.6 versus 45.3 months, $p=0.035)$ [24] and Creasy et al. demonstrated an inferior HR of $1.22(95 \%$ CI, 1.02-1.45; $p=0.028$ ) for resected CRLM from right-sided CC [25]. Similar to our series, Makowiec et al. showed no significant difference in 5-year OS between patients with resected CRLM originating from right- versus left-sided CRC ( $p=0.64)$ [23]. Gu et al. [27] found an inferior OS $(p=0.042)$ and higher recurrence rates $(p=0.029)$ for right-sided versus left-sided CRC following RFA. Though Zhou et al. did find a difference in progression-free survival favoring left-sided CRC $(p=0.012)$, there was no significant difference in OS $(p=0.583)$ following MWA [28].

RAS mutations are present in approximately $40 \%$ of patients with CRC, substantially affecting survival outcomes following primary tumor resection and CRLM resection [35-38]. Zhang et al. revealed increased rates of micrometastases $(p<0.001)$ and reduced margin size resulting in increased R1 resections $(p=0.002)$ in patients with KRAS mutations following liver surgery [39]. In multivariate analysis, KRAS mutation (HR, 1.495; 95\% CI, 1.069-2.092; $p=0.019)$ and margin status (HR, 1.560; 95\% CI, 1.017-3.033; $p=0.043)$ were significantly correlated with hepatic disease recurrence. Therefore, in patients with KRAS mutated CRLMs, Zhang et al. advocated wider surgical margins. In addition, Brudvik et al. reported an association between RAS mutation and positive margins in multivariate analysis (HR, 2.439; 95\% CI, 1.300-4.575; $p=0.005)$ [40]. RAS mutation (HR, 1.629; 95\% CI, 1.013-2.620; $p=0.044)$ and positive margins (HR, 3.360; 95\% CI, 1.741-6.485; $p<0.001)$ both correlated with reduced OS rates in multivariate analysis. Brudvik et al. proposed margin sizes over $10 \mathrm{~mm}$, as suggested earlier by Are et al. as well [40,41]. Achterberg et al. showed that near-infrared fluorescence imaging using indocyanine green may contribute to acquiring these tumor-negative resections in minimal invasive surgery [42].

To assess the prognostic role of RAS status, Odisio et al. compared patients with RAS wildtype to patients with RAS mutation following thermal ablation [43]. LTP was 
found in 39\% of patients with RAS mutated CRLMs and in 14\% of patients with RAS wildtype CRLMs ( $p=0.007)$. Three-year LTPFS was $35 \%$ compared to $71 \%$ of, respectively, RAS mutation and RAS wildtype (HR 3.01, 95\% CI 1.60-5.77, $p=0.001$ ). Furthermore, Shady et al. showed KRAS to be a significant predictor of LTPFS following thermal ablation in univariate analysis (HR, 1.5; 95\% CI, $0.89-2.7 ; p=0.12)$ [44]. They proposed peri-ablational safety margins $>6 \mathrm{~mm}$ to obtain LC in patients with KRAS mutated CRLMs, as margins of 1-5 mm after thermal ablation in the KRAS group showed inferior LTP rates $(p=0.018)$ [44]. Similar to our work, Odisio et al. and Shady et al. performed ablations without consideration of RAS mutation status. Based on these and other previous studies and based on the currently presented results, we suggest peri-ablational minimum safety margins of $>5 \mathrm{~mm}$ for RAS-wildtype and $>10 \mathrm{~mm}$ for RAS-mutated CRLM [40,43,45-49]. Recent and ongoing developments in thermal ablation techniques, comprising antenna, probe, and generator design, improved image-guidance, real-time navigation, and imagefusion and registration and the use of confirmation software to reliably assess margins, contribute in the achievement of these sufficient peri-ablational safety margins [45-51].

The high number of patients, procedures and tumors allowed sufficiently powered statistical analyses, which strengthened this study. The choice of treatment and patient selection was based on multidisciplinary tumor board evaluations where primary tumor sidedness, RAS and BRAF mutations, and MSI status were previously disregarded in decision making. Though confounding was limited by the use of Cox proportional hazards and regression models including multivariable analysis, residual confounding cannot be ruled out regarding the subgroup analysis for resection and thermal ablation. Because RAS, BRAF, and MSI status were not routinely established and, hence, often unknown, the analyses of the impact of RAS and BRAF mutations and MSI status were less robustly powered, increasing the risk of bias. Additionally, technical developments in resection and thermal ablation over the long study period may have caused population bias and the local treatment techniques do not automatically represent the current global standards of care.

\section{Conclusions}

To conclude, for patients undergoing partial hepatectomy or thermal ablation for CRLM, BRAF mutations, and, if not treated with immunotherapy, MS instability were associated with a higher probability of relapse and death. RAS mutated tumors were at higher risk for an incomplete resection or ablation, suggesting the necessity to widen margins whenever feasible. Margins $>5 \mathrm{~mm}$ and $>10 \mathrm{~mm}$ are advised for RAS wildtype and RAS mutated CRLM, respectively. Knowledge regarding BRAF and RAS mutations and MSI status improves clinical judgment and decision making and it may improve outcome by reducing the number of repeat treatments.

Author Contributions: Conceptualization, M.D., M.P.v.d.T. and M.R.M.; methodology, M.D., S.N., F.E.F.T. and B.I.L.-W.; software, M.D. and B.I.L.-W.; validation, M.D., S.N., R.S.P., F.E.F.T., B.G., E.A.C.S., J.O., H.J.S., J.J.J.d.V., K.S.V., B.I.L.-W., M.P.v.d.T. and M.R.M.; formal analysis, M.D., S.N., F.E.F.T. and B.I.L.-W.; investigation, M.D. and S.N.; resources, M.D. and B.I.L.-W.; data curation, M.D., S.N., R.S.P., E.A.C.S., J.O., M.P.v.d.T. and M.R.M.; writing—original draft preparation, M.D.; writing—review and editing, M.D., S.N., R.S.P., F.E.F.T., B.G., E.A.C.S., J.O., H.J.S., J.J.J.d.V., K.S.V., B.I.L.-W., M.P.v.d.T. and M.R.M.; visualization, M.D., S.N., F.E.F.T., M.P.v.d.T. and M.R.M.; supervision, M.P.v.d.T. and M.R.M.; project administration, M.D.; funding acquisition, not applicable. All authors have read and agreed to the published version of the manuscript.

Funding: This research received no external funding.

Institutional Review Board Statement: The study was approved by the affiliated Institutional Review Board (METc Amsterdam University Medical Centers, location VUmc: 2021.0121, 14 May 2021).

Informed Consent Statement: Patient consent was waived as the study was not subject to the Medical Research Involving Human Subjects Act judged by the affiliated Institutional Review Board (METc VUmc: 2021.0121). 
Data Availability Statement: The data presented in this study are available on request from the corresponding author.

Conflicts of Interest: The authors declare no conflict of interest.

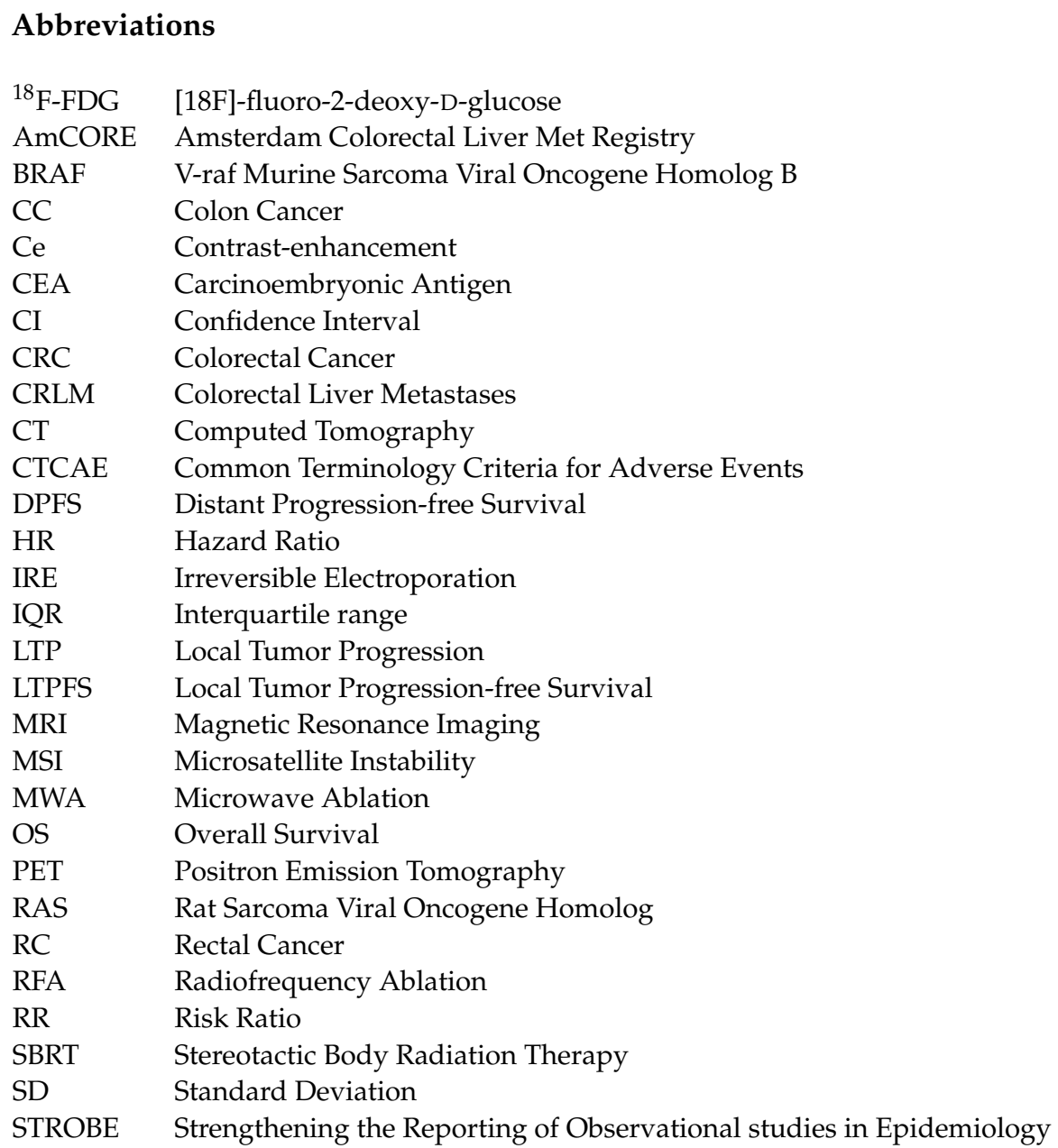

\section{References}

1. WHO. Estimated Age-Standardized Incidence Rates (World) in 2020, All Cancers, Both Sexes, All Ages. Available online: http:/ / gco.iarc.fr/today/online-analysis-map (accessed on 4 March 2021).

2. Engstrand, J.; Nilsson, H.; Stromberg, C.; Jonas, E.; Freedman, J. Colorectal cancer liver metastases-A population-based study on incidence, management and survival. BMC Cancer 2018, 18, 78. [CrossRef] [PubMed]

3. Meijerink, M.R.; Puijk, R.S.; van Tilborg, A.; Henningsen, K.H.; Fernandez, L.G.; Neyt, M.; Heymans, J.; Frankema, J.S.; de Jong, K.P.; Richel, D.J.; et al. Radiofrequency and Microwave Ablation Compared to Systemic Chemotherapy and to Partial Hepatectomy in the Treatment of Colorectal Liver Metastases: A Systematic Review and Meta-Analysis. Cardiovasc Interv. Radiol 2018, 41, 1189-1204. [CrossRef] [PubMed]

4. Scheele, J.; Stangl, R.; Altendorf-Hofmann, A. Hepatic metastases from colorectal carcinoma: Impact of surgical resection on the natural history. Br. J. Surg. 1990, 77, 1241-1246. [CrossRef] [PubMed]

5. Stangl, R.; Altendorf-Hofmann, A.; Charnley, R.M.; Scheele, J. Factors influencing the natural history of colorectal liver metastases. Lancet 1994, 343, 1405-1410. [CrossRef]

6. Wagner, J.S.; Adson, M.A.; van Heerden, J.A.; Adson, M.H.; Ilstrup, D.M. The natural history of hepatic metastases from colorectal cancer. A comparison with resective treatment. Ann. Surg. 1984, 199, 502-508. [CrossRef]

7. Yang, Q.; Liao, F.; Huang, Y.; Jiang, C.; Liu, S.; He, W.; Kong, P.; Zhang, B.; Xia, L. Longterm effects of palliative local treatment of incurable metastatic lesions in colorectal cancer patients. Oncotarget 2016, 7, 21034-21045. [CrossRef]

8. Gleisner, A.L.; Choti, M.A.; Assumpcao, L.; Nathan, H.; Schulick, R.D.; Pawlik, T.M. Colorectal liver metastases: Recurrence and survival following hepatic resection, radiofrequency ablation, and combined resection-radiofrequency ablation. Arch. Surg. 2008, 143, 1204-1212. [CrossRef] 
9. Abdalla, E.K.; Vauthey, J.N.; Ellis, L.M.; Ellis, V.; Pollock, R.; Broglio, K.R.; Hess, K.; Curley, S.A. Recurrence and outcomes following hepatic resection, radiofrequency ablation, and combined resection/ablation for colorectal liver metastases. Ann. Surg. 2004, 239, 818-825, discussion 825-827. [CrossRef]

10. Gillams, A.; Goldberg, N.; Ahmed, M.; Bale, R.; Breen, D.; Callstrom, M.; Chen, M.H.; Choi, B.I.; de Baere, T.; Dupuy, D.; et al. Thermal ablation of colorectal liver metastases: A position paper by an international panel of ablation experts, The Interventional Oncology Sans Frontieres meeting 2013. Eur. Radiol. 2015, 25, 3438-3454. [CrossRef]

11. Vasiniotis Kamarinos, N.; Kaye, E.A.; Sofocleous, C.T. Image-Guided Thermal Ablation for Colorectal Liver Metastases. Tech. Vasc. Interv. Radiol. 2020, 23, 100672. [CrossRef]

12. Nieuwenhuizen, S.; Puijk, R.S.; van den Bemd, B.; Aldrighetti, L.; Arntz, M.; van den Boezem, P.B.; Bruynzeel, A.M.E.; Burgmans, M.C.; de Cobelli, F.; Coolsen, M.M.E.; et al. Resectability and Ablatability Criteria for the Treatment of Liver Only Colorectal Metastases: Multidisciplinary Consensus Document from the COLLISION Trial Group. Cancers 2020, 12, 1779. [CrossRef] [PubMed]

13. Puijk, R.S.; Ruarus, A.H.; Vroomen, L.; van Tilborg, A.; Scheffer, H.J.; Nielsen, K.; de Jong, M.C.; de Vries, J.J.J.; Zonderhuis, B.M.; Eker, H.H.; et al. Colorectal liver metastases: Surgery versus thermal ablation (COLLISION)—A phase III single-blind prospective randomized controlled trial. BMC Cancer 2018, 18, 821. [CrossRef]

14. Fong, Y.; Fortner, J.; Sun, R.L.; Brennan, M.F.; Blumgart, L.H. Clinical score for predicting recurrence after hepatic resection for metastatic colorectal cancer: Analysis of 1001 consecutive cases. Ann. Surg. 1999, 230, 309-318. [CrossRef] [PubMed]

15. Sofocleous, C.T.; Petre, E.N.; Gonen, M.; Brown, K.T.; Solomon, S.B.; Covey, A.M.; Alago, W.; Brody, L.A.; Thornton, R.H.; D'Angelica, M.; et al. CT-guided radiofrequency ablation as a salvage treatment of colorectal cancer hepatic metastases developing after hepatectomy. J. Vasc. Interv. Radiol. 2011, 22, 755-761. [CrossRef] [PubMed]

16. Shady, W.; Petre, E.N.; Gonen, M.; Erinjeri, J.P.; Brown, K.T.; Covey, A.M.; Alago, W.; Durack, J.C.; Maybody, M.; Brody, L.A.; et al. Percutaneous radiofrequency ablation of colorectal cancer liver metastases: Factors affecting outcomes-a 10-year experience at a single center. Radiology 2016, 278, 601-611. [CrossRef]

17. Brudvik, K.W.; Jones, R.P.; Giuliante, F.; Shindoh, J.; Passot, G.; Chung, M.H.; Song, J.; Li, L.; Dagenborg, V.J.; Fretland, A.A.; et al. RAS Mutation Clinical Risk Score to Predict Survival After Resection of Colorectal Liver Metastases. Ann. Surg. 2019, 269, 120-126. [CrossRef] [PubMed]

18. Gervaz, P.; Bucher, P.; Morel, P. Two colons-two cancers: Paradigm shift and clinical implications. J. Surg. Oncol. 2004, 88, 261-266. [CrossRef]

19. Kalantzis, I.; Nonni, A.; Pavlakis, K.; Delicha, E.M.; Miltiadou, K.; Kosmas, C.; Ziras, N.; Gkoumas, K.; Gakiopoulou, H. Clinicopathological differences and correlations between right and left colon cancer. World J. Clin. Cases 2020, 8, $1424-1443$. [CrossRef]

20. Benedix, F.; Meyer, F.; Kube, R.; Kropf, S.; Kuester, D.; Lippert, H.; Roessner, A.; Kruger, S. Influence of anatomical subsite on the incidence of microsatellite instability, and KRAS and BRAF mutation rates in patients with colon carcinoma. Pathol. Res. Pract. 2012, 208, 592-597. [CrossRef]

21. Petrelli, F.; Tomasello, G.; Borgonovo, K.; Ghidini, M.; Turati, L.; Dallera, P.; Passalacqua, R.; Sgroi, G.; Barni, S. Prognostic Survival Associated With Left-Sided vs Right-Sided Colon Cancer A Systematic Review and Meta-analysis. JAMA Oncol. 2017, 3, 211-219. [CrossRef]

22. Gasser, E.; Braunwarth, E.; Riedmann, M.; Cardini, B.; Fadinger, N.; Presl, J.; Klieser, E.; Ellmerer, P.; Dupre, A.; Imai, K.; et al. Primary tumour location affects survival after resection of colorectal liver metastases: A two-institutional cohort study with international validation, systematic meta-analysis and a clinical risk score. PLoS ONE 2019, 14, e0217411. [CrossRef]

23. Makowiec, F.; Menzel, M.; Bronsert, P.; Holzner, P.A.; Klock, A.; Lang, S.A.; Fichtner-Feigl, S.; Neeff, H.P. Does the site of primary colorectal cancer influence the outcome after resection of isolated liver metastases? Dig. Liver Dis. 2018, 50, 1088-1092. [CrossRef] [PubMed]

24. Dupre, A.; Malik, H.Z.; Jones, R.P.; Diaz-Nieto, R.; Fenwick, S.W.; Poston, G.J. Influence of the primary tumour location in patients undergoing surgery for colorectal liver metastases. Eur. J. Surg. Oncol. 2018, 44, 80-86. [CrossRef] [PubMed]

25. Creasy, J.M.; Sadot, E.; Koerkamp, B.G.; Chou, J.F.; Gonen, M.; Kemeny, N.E.; Saltz, L.B.; Balachandran, V.P.; Peter Kingham, T.; DeMatteo, R.P.; et al. The Impact of Primary Tumor Location on Long-Term Survival in Patients Undergoing Hepatic Resection for Metastatic Colon Cancer. Ann. Surg. Oncol. 2018, 25, 431-438. [CrossRef] [PubMed]

26. Zhang, Y.; Wang, Y.; Yuan, Y.; Qiu, J.; Qiu, Y.; He, W.; Zheng, Y.; Wang, Z.; Gu, Y.; Lu, Z.; et al. Primary tumor location affects recurrence-free survival for patients with colorectal liver metastases after hepatectomy: A propensity score matching analysis. World J. Surg. Oncol. 2020, 18, 98. [CrossRef]

27. Gu, Y.; Huang, Z.; Gu, H.; Gao, F.; Zhang, T.; Huang, S.; Huang, J. Does the Site of the Primary Affect Outcomes When Ablating Colorectal Liver Metastases with Radiofrequency Ablation? CardioVascular Interv. Radiol. 2018, 41, 912-919. [CrossRef]

28. Zhou, F.B.; Yu, X.L.; Liang, P.; Han, Z.Y.; Cheng, Z.G.; Yu, J.; Liu, F.Y.; Hu, Y. Does primary tumor location impact the prognosis of colorectal liver metastases patients after microwave ablation?-Lessons from 10 years' experience. Oncotarget 2017, 8, 100791-100800. [CrossRef]

29. von Elm, E.; Altman, D.G.; Egger, M.; Pocock, S.J.; Gotzsche, P.C.; Vandenbroucke, J.P.; Initiative, S. The Strengthening the Reporting of Observational Studies in Epidemiology (STROBE) statement: Guidelines for reporting observational studies. J. Clin. Epidemiol. 2008, 61, 344-349. [CrossRef] 
30. Crocetti, L.; de Baere, T.; Lencioni, R. Quality improvement guidelines for radiofrequency ablation of liver tumours. CardioVasc. Interv. Radiol. 2010, 33, 11-17. [CrossRef]

31. Comprehensive Cancer Organisation The Netherlands (I.K.N.L.). National Evidence-Based Guideline. In Colorectaalcarcinoom Available online: http:/ / oncoline.nl/2014 (accessed on 4 March 2021).

32. Common Terminology Criteria for Adverse Events (CTCAE) v5.0. Available online: https:/ / ctep.cancer.gov/protocoldevelopment/ electronic_applications/docs/CTCAE_v5_Quick_Reference_8.5x11.pdf (accessed on 25 November 2020).

33. IBM Corp. IBM®SPSS®Statistics for Windows, version 26.0; IBM Corp: Armonk, NY, USA, 2019.

34. R Core Team. R: A language and environment for statistical computing. In $R$ for Windows Version 4.0.3; R Foundation for Statistical Computing: Vienna, Austria, 2019.

35. Van Cutsem, E.; Kohne, C.H.; Lang, I.; Folprecht, G.; Nowacki, M.P.; Cascinu, S.; Shchepotin, I.; Maurel, J.; Cunningham, D.; Tejpar, S.; et al. Cetuximab plus irinotecan, fluorouracil, and leucovorin as first-line treatment for metastatic colorectal cancer: Updated analysis of overall survival according to tumor KRAS and BRAF mutation status. J. Clin. Oncol. 2011, 29, 2011-2019. [CrossRef]

36. Vauthey, J.N.; Zimmitti, G.; Kopetz, S.E.; Shindoh, J.; Chen, S.S.; Andreou, A.; Curley, S.A.; Aloia, T.A.; Maru, D.M. RAS mutation status predicts survival and patterns of recurrence in patients undergoing hepatectomy for colorectal liver metastases. Ann. Surg. 2013, 258, 619-626. [CrossRef]

37. Taieb, J.; Zaanan, A.; Le Malicot, K.; Julie, C.; Blons, H.; Mineur, L.; Bennouna, J.; Tabernero, J.; Mini, E.; Folprecht, G.; et al. Prognostic Effect of BRAF and KRAS Mutations in Patients with Stage III Colon Cancer Treated with Leucovorin, Fluorouracil, and Oxaliplatin with or Without Cetuximab: A Post Hoc Analysis of the PETACC-8 Trial. JAMA Oncol. 2016, 2, 643-653. [CrossRef] [PubMed]

38. Brudvik, K.W.; Kopetz, S.E.; Li, L.; Conrad, C.; Aloia, T.A.; Vauthey, J.N. Meta-analysis of KRAS mutations and survival after resection of colorectal liver metastases. Br. J. Surg. 2015, 102, 1175-1183. [CrossRef] [PubMed]

39. Zhang, Q.; Peng, J.; Ye, M.; Weng, W.; Tan, C.; Ni, S.; Huang, D.; Sheng, W.; Wang, L. KRAS Mutation Predicted More Mirometastases and Closer Resection Margins in Patients with Colorectal Cancer Liver Metastases. Ann. Surg. Oncol. 2020, 27, 1164-1173. [CrossRef] [PubMed]

40. Brudvik, K.W.; Mise, Y.; Chung, M.H.; Chun, Y.S.; Kopetz, S.E.; Passot, G.; Conrad, C.; Maru, D.M.; Aloia, T.A.; Vauthey, J.N. RAS Mutation Predicts Positive Resection Margins and Narrower Resection Margins in Patients Undergoing Resection of Colorectal Liver Metastases. Ann. Surg. Oncol. 2016, 23, 2635-2643. [CrossRef]

41. Are, C.; Gonen, M.; Zazzali, K.; Dematteo, R.P.; Jarnagin, W.R.; Fong, Y.; Blumgart, L.H.; D'Angelica, M. The impact of margins on outcome after hepatic resection for colorectal metastasis. Ann. Surg. 2007, 246, 295-300. [CrossRef]

42. Achterberg, F.B.; Sibinga Mulder, B.G.; Meijer, R.P.J.; Bonsing, B.A.; Hartgrink, H.H.; Mieog, J.S.D.; Zlitni, A.; Park, S.M.; Farina Sarasqueta, A.; Vahrmeijer, A.L.; et al. Real-time surgical margin assessment using ICG-fluorescence during laparoscopic and robot-assisted resections of colorectal liver metastases. Ann. Transl. Med. 2020, 8, 1448. [CrossRef]

43. Odisio, B.C.; Yamashita, S.; Huang, S.Y.; Harmoush, S.; Kopetz, S.E.; Ahrar, K.; Chun, Y.S.; Conrad, C.; Aloia, T.A.; Gupta, S.; et al. Local tumour progression after percutaneous ablation of colorectal liver metastases according to RAS mutation status. Br. J. Surg. 2017, 104, 760-768. [CrossRef]

44. Shady, W.; Petre, E.N.; Vakiani, E.; Ziv, E.; Gonen, M.; Brown, K.T.; Kemeny, N.E.; Solomon, S.B.; Solit, D.B.; Sofocleous, C.T. Kras mutation is a marker of worse oncologic outcomes after percutaneous radiofrequency ablation of colorectal liver metastases. Oncotarget 2017, 8, 66117-66127. [CrossRef]

45. Wang, X.; Sofocleous, C.T.; Erinjeri, J.P.; Petre, E.N.; Gonen, M.; Do, K.G.; Brown, K.T.; Covey, A.M.; Brody, L.A.; Alago, W.; et al. Margin size is an independent predictor of local tumor progression after ablation of colon cancer liver metastases. Cardiovasc Interv. Radiol. 2013, 36, 166-175. [CrossRef]

46. Shady, W.; Petre, E.N.; Do, K.G.; Gonen, M.; Yarmohammadi, H.; Brown, K.T.; Kemeny, N.E.; D'Angelica, M.; Kingham, P.T.; Solomon, S.B.; et al. Percutaneous Microwave versus Radiofrequency Ablation of Colorectal Liver Metastases: Ablation with Clear Margins (A0) Provides the Best Local Tumor Control. J. Vasc. Interv. Radiol. 2018, 29, 268-275.e1. [CrossRef] [PubMed]

47. Solbiati, M.; Muglia, R.; Goldberg, S.N.; Ierace, T.; Rotilio, A.; Passera, K.M.; Marre, I.; Solbiati, L. A novel software platform for volumetric assessment of ablation completeness. Int. J. Hyperth. 2019, 36, 337-343. [CrossRef]

48. Kaye, E.A.; Cornelis, F.H.; Petre, E.N.; Tyagi, N.; Shady, W.; Shi, W.; Zhang, Z.; Solomon, S.B.; Sofocleous, C.T.; Durack, J.C. Volumetric 3D assessment of ablation zones after thermal ablation of colorectal liver metastases to improve prediction of local tumor progression. Eur. Radiol. 2019, 29, 2698-2705. [CrossRef] [PubMed]

49. Laimer, G.; Jaschke, N.; Schullian, P.; Putzer, D.; Eberle, G.; Solbiati, M.; Solbiati, L.; Goldberg, S.N.; Bale, R. Volumetric assessment of the periablational safety margin after thermal ablation of colorectal liver metastases. Eur. Radiol. 2021. [CrossRef]

50. Van Tilborg, A.A.; Scheffer, H.J.; van der Meijs, B.B.; van Werkum, M.H.; Melenhorst, M.C.; van den Tol, P.M.; Meijerink, M.R. Transcatheter CT hepatic arteriography-guided percutaneous ablation to treat ablation site recurrences of colorectal liver metastases: The incomplete ring sign. J. Vasc. Interv. Radiol. 2015, 26, 583-587.e581. [CrossRef]

51. Puijk, R.S.; Ruarus, A.H.; Scheffer, H.J.; Vroomen, L.; van Tilborg, A.; de Vries, J.J.J.; Berger, F.H.; van den Tol, P.M.P.; Meijerink, M.R. Percutaneous Liver Tumour Ablation: Image Guidance, Endpoint Assessment, and Quality Control. Can. Assoc. Radiol. J. 2018, 69, 51-62. [CrossRef] 